\title{
Endoscopic Resection for Early Gastric Cancer: What is the Limit?
}

\author{
Philip W. Y. Chiu, MD and Paul B. S. Lai, MD \\ Department of Surgery, Prince of Wales Hospital, The Chinese University of Hong Kong, Hong Kong SAR, China
}

Majority of the gastric cancers in the world occurred in Asia, especially in Japan and Korea. ${ }^{1}$ The prevalence of early gastric cancer (EGC) is up to $60 \%$ of all gastric cancers detected in these two countries, where their governments have adopted a screening program for gastric cancer. Pioneered by Japanese endoscopists, endoscopic submucosal dissection (ESD) has become the current standard of treatment for early gastric cancer. ${ }^{2}$ Prospective large-scale clinical studies with 500-1,000 cases showed that the average operative time of ESD ranged from 60 to $80 \mathrm{~min}$, with en bloc resection rate of more than $90 \%$. $^{2,3}$ Three retrospective cohort studies comparing conventional endoscopic mucosal resection (EMR) against ESD for treatment of early gastric cancer showed that ESD achieved a higher en bloc resection rate and lower local recurrence rate compared with EMR. ${ }^{4-6}$ Although ESD is highly effective for treatment of intramucosal gastric cancer, those with high risk of nodal metastasis cannot be adequately cured by endoscopic resection alone.

Japanese Gastric Cancer Association has developed guidelines for treatment of gastric cancer. In the past, only early differentiated intramucosal gastric cancer with size of less than $20 \mathrm{~mm}$ was indicated for endoscopic treatment. Gotoda et al. reviewed the histopathology of 5,625 patients with EGC who underwent radical gastrectomy and lymph node dissection. ${ }^{7}$ The study confirmed that none of 1,230 differentiated carcinomas less than $30 \mathrm{~mm}$ had nodal metastasis, and no nodal metastasis was found in 929 of these without ulceration regardless of tumor size. For tumors of SM1 invasion and less than $30 \mathrm{~mm}$ in size, none

(C) Society of Surgical Oncology 2015

First Received: 26 November 2014; Published Online: 10 February 2015

P. B. S. Lai, MD

e-mail: paullai@surgery.cuhk.edu.hk was shown to have nodal metastasis. Shimada et al. reviewed 1,051 patients with EGC who underwent radical gastrectomy, and the nodal metastasis rate for intramucosal tumors was $2.3 \%$. For those with submucosal invasion, there was a significant rate of nodal metastasis of $19.8 \%{ }^{8}$ The recommended indication for endoscopic resection of EGC was expanded, especially when techniques of ESD became available.

Submucosal infiltration by gastric cancer has been a known risk factor to nodal metastasis. Ahn et al. compared the outcomes of early gastric cancer in 1,370 patients who received endoscopic resection under both absolute indication and expanded indication. ${ }^{9}$ Among these, 119 patients had superficial submucosal invasive gastric cancer with a size of less than $30 \mathrm{~mm}$ treated by endoscopic resection. These cases would be considered as curative in the expanded criteria. However, 34 patients subsequently received surgery and 1 patient who had no residue cancer in the stomach was found to have a metastatic perigastric lymph node. Therefore, even with the expanded criteria for endoscopic resection, caution should be exercised in choosing the appropriate treatments for superficial submucosal early gastric cancer.

In this issue, Eom et al. examined the optimal submucosal invasive of early gastric cancer suitable for endoscopic resection in 1,322 patients who received radical gastrectomy. ${ }^{10}$ Among the 1,322 patients who received curative gastrectomy with standard nodal dissection for submucosal gastric cancer, $18.8 \%$ was found to have a positive lymph node. This study showed that a cutoff point of $300 \mu \mathrm{m}$ of submucosal infiltration achieved the highest negative predictive value of $98 \%$ for predicting lymph node metastasis. The authors proposed for large-scale study to validate the cutoff value. Son et al. examined the risk factors for lymph node metastasis in early gastric cancers treated by endoscopic resection. ${ }^{11}$ The important risk factors for nodal metastasis included submucosal invasion, 
lymphovascular permeation, mixed undifferentiated histology, and size of tumor larger than $20 \mathrm{~mm}$. Kang et al. reported another retrospective study on histopathological features to predict nodal metastasis for EGC. ${ }^{12}$ The increasing size of the tumor, elevated macroscopic type, depth of invasion, and lymphovascular permeation were associated with risk of lymph node metastasis. These studies defined submucosal infiltration according to Japanese guidelines for treatment of SM1 $<500$ or SM2 $>500 \mu \mathrm{m} .{ }^{13}$ The current study illustrated that the overall incidence of nodal metastasis within $500 \mu \mathrm{m}$ infiltration was $9.6 \%$, whereas those with infiltration of more than $300 \mu \mathrm{m}$ had significantly higher risk of nodal metastasis. Practically, clinician should consider salvage surgery if the depth of invasion was more than $300 \mu \mathrm{m}$. However, the area under curve (AUC) for depth of submucosal invasion to predict nodal metastasis was only 0.664 . The consideration of other risk factors, including lymphovascular permeation and size of the tumor as a composite prediction score, will probably improve the AUC.

One of the interesting issues raised in this article is the standard of measurement for submucosal invasion. The authors attributed the difference in high incidence of nodal metastasis for the current study to that reported by Gotoda et al. to difference in measurement of submucosal invasion. $^{7}$ The inaccuracy of measurement of submucosal infiltration could be related to an obscured muscularis mucosa due to tumor infiltration if the measurement started from below muscularis mucosa.

There is still controversy about whether ESD is adequate for treatment of early gastric cancer with superficial submucosal invasion. In real-life clinical practice, majority of the early gastric cancers with superficial submucosal infiltration are discovered upon histological assessment after endoscopic or surgical treatment. The search of optimal submucosal infiltration for endoscopic resection of EGC will be more related to the decision for salvage gastrectomy after endoscopic resection. Meanwhile, compared with surgery, endoscopic submucosal dissection achieved significantly better perioperative outcomes with lower morbidities compared with gastrectomy for treatment of early gastric cancers. ${ }^{14}$

ACKNOWLEDGMENT The authors have no conflict of interest to declare.

\section{REFERENCES}

1. Leung WK, Wu MS, Kakugawa Y, Kim JJ, Yeoh KG, Goh KL, Wu KC, Wu DC, Sollano J, Kachintorn U, Gotoda T, Lin JT, You
WC, Ng EK, Sung JJ; Asia Pacific Working Group on Gastric Cancer. Screening for gastric cancer in Asia: current evidence and practice. Lancet Oncol. 2008;9(3):279-87.

2. Yamamoto H. Endoscopic submucosal dissection-current success and future directions. Nat Rev Gastroenterol Hepatol. 2012;9:519-29.

3. Chiu PW. Novel endoscopic therapeutics for early gastric cancer. Clin Gastroenterol Hepatol. 2014;12(1):120-5.

4. Tanabe S, Ishido K, Huguchi K, et al. Long term outcomes of endoscopic submucosal dissection for early gastric cancer: a retrospective comparison with conventional endoscopic resection in a single center. Gastric Cancer. 2013.

5. Watanabe K, Ogata S, Kawazoe S, Watanabe K, Koyama T, Kajiwara T, Shimoda Y, Takase Y, Irie K, Mizuguchi M, Tsunada S, Iwakiri R, Fujimoto K. Clinical outcomes of EMR for gastric tumors: historical pilot evaluation between endoscopic submucosal dissection and conventional mucosal resection. Gastrointest Endosc. 2006;63(6):776-82.

6. Oka S, Tanaka S, Kaneko I, Mouri R, Hirata M, Kawamura T, Yoshihara M, Chayama K. Advantage of endoscopic submucosal dissection compared with EMR for early gastric cancer. Gastrointest Endosc. 2006;64(6):877-83.

7. Gotoda T, Yanagisawa A, Sasako M, et al. Incidence of lymph node metastasis from early gastric cancer: estimation with a large number of cases at two large centers. Gastric Cancer. 2000;3: 219-25.

8. Shimada S, Yagi Y, Shiomori K, Shiomori K, Honmyo U, Hayashi N, Matsuo A, Marutsuka T, Ogawa M. Characterization of early gastric cancer and proposal of the optimal therapeutic strategy. Surgery. 2001;129:714-9.

9. Ahn JY, Jung HY, Choi KD, Choi JY, Kim MY, Lee JH, Choi KS, Kim do H, Song HJ, Lee GH, Kim JH, Park YS. Endoscopic and oncologic outcomes after endoscopic resection for early gastric cancer: 1370 case of absolute and extended indications. Gastrointest Endosc. 2011;74:485-93.

10. Eom BW, Yu JS, Ryu KW, Kook MC, Kim YI, Cho SJ, Lee JY, Kim CG, Choi IJ, Yoon H, Kim YW. Optimal submucosal invasive of early gastric cancer for endoscopic resection. Ann Surg Oncol. 2014.

11. Son SY, Park JY, Ryu KW, Eom BW, Yoon HM, Cho SJ, Lee JY, Kim CG, Lee JH, Kook MC, Choi IJ, Kim YW. The risk factors for lymph node metastasis in early gastric cancer patients who underwent endoscopic resection: is the minimal lymph node dissection applicable? A retrospective study. Surg Endosc. 2013;27(9):3247-53.

12. Kang HJ, Kim DH, Jeon TY, Lee SH, Shin N, Chae SH, Kim GH, Song GA, Kim DH, Srivastava A, Park do Y, Lauwers GY. Lymph node metastasis from intestinal-type early gastric cancer: experience in a single institution and reassessment of the extended criteria for endoscopic submucosal dissection. Gastrointest Endosc. 2010;72(3):508-15.

13. Japanese gastric cancer treatment guidelines 2010 (version 3). Gastric Cancer. 2011;14:113-23.

14. Chiu PW, Teoh AY, To KF, Wong SK, Liu SY, Lam CC, Yung MY, Chan FK, Lau JY, Ng EK. Endoscopic submucosal dissection (ESD) compared with gastrectomy for treatment of early gastric neoplasia: a retrospective cohort study. Surg Endosc. 2012;26(12):3584-91. 